NBER WORKING PAPER SERIES

\title{
MONETARY POLICY AND THE TERM \\ STRUCTURE OF INTEREST RATES
}

\author{
Bennett T. McCallum
}

Working Paper No. 4938

\section{NATIONAL BUREAU OF ECONOMIC RESEARCH 1050 Massachusetts Avenue \\ Cambridge, MA 02138 \\ November 1994}

For helpful comments on an earlier draft, the author is indebted to John Campbell, Tim Cook, Spencer Dale, Eugene Fama, Kenneth Froot, Marvin Goodfriend, Charles Goodheart. Greg Mankiw, Allan Meltzer, Danny Quah, Tony Smith and Julian Wiseman. This paper is part of NBER's programs in Economic Fluctuations and Monetary Economics. Any opinions expressed are those of the author and not of the National Bureau of Economic Research.

(C) 1994 by Bennett T. McCallum. All rights reserved. Short sections of text, not to exceed two paragraphs, may be quoted without explicit permission provided that full credit, including ( $\odot$ notice, is given to the source. 
NBER Working Paper *4938

November 1994

\title{
MONETARY POLICY AND THE TERM \\ STRUCTURE OF INTEREST RATES
}

\begin{abstract}
This paper addresses a prominent empirical failure of the expectations theory of the term structure of interest rates under the assumption of rational expectations. This failure concerns the magnitude of slope coefficients in regressions of short rate (or long-rate) changes on longshort spreads. It is shown that the anomalous empirical findings can be rationalized with the expectations theory by recognition of an exogenous random (but possibly autoregressive) term premium plus the assumption that monetary policy involves smoothing of an interest rate instrument -- the short rate -- together with the responses to the prevailing level of the spread.
\end{abstract}

Bennett T. McCallum

Graduate School of Industrial Administration

Carnegie Mellon University

Pittsburgh, PA 15213-3890

and NBER 


\section{Introduction}

In a recent paper. McCallum (1994) argues that a prominent empirical puzzle involving exchange rate behavior--namely, the drastic apparent fallure of uncovered interest parity--can be rationalized as a consequence of systematic monetary policy behavior that has been ignored in most previous studies. $^{1}$ Here $1 \mathrm{t}$ will be argued that a similar result is applicable in the context of an apparent fallure of the expectations theory of the term structure of interest rates. In particular, the fallure of short-rate (and long-rate) changes to be related as predicted to prevalling long-short spreads is shown to be a plausible consequence of monetary policy behavior that features interest rate smoothing in combination with policy responses to movements in the long-short spread. ${ }^{2}$ This explanation is entirely consistent with, but more general and more fully developed than, the one proposed in a notable study by Mankiw and Miron (1986). ${ }^{3}$

The paper's organization is as follows. In Section II, the term-structure puzzle is reviewed and the paper's rationalization is developed for the simplest two-perlod case. Then in Section III, the analysis is extended to long rates of greater maturity. Additional evidence is developed in Section IV and concluding remarks appear in Section $V$.

\section{Two-Perlod Case}

In this section we consider the issue and our proposed explanation for the two-perlod case, 1.e., for the relationship between yields on one-period and two-perlod bonds, denoted $r_{t}$ and $R_{t}$ respectively. Assuming that the securities in question are discount bonds, the expectations theory of the term structure posits that the "long" rate $R_{t}$ is related to $r_{t}$ and the expected future short rate $E_{t} r_{t+1}$ as follows: ${ }^{4}$

(1) $\quad R_{t}=0.5\left(r_{t}+E_{t} r_{t+1}\right)+\xi_{t}$.

Here $E_{t} r_{t+1}=E\left(r_{t+1} \mid \Omega_{t}\right)$ with $\Omega_{t}=\left\{r_{t}, r_{t+1}, \ldots, R_{t}, R_{t-1}, \ldots\right\}$ so we are 
assuming rational expectations. The term $\xi_{t}$ is a "term premium" that is of ten assumed constant. Defining the expectational error $\varepsilon_{t+1}=r_{t+1}-$ $E_{t} r_{t+1}$, equation (1) implies

$$
1 / 2\left(r_{t+1}-r_{t}\right)=\left(R_{t}-r_{t}\right)-\xi_{t}+1 / 2 \varepsilon_{t+1}
$$

Then $1 f \xi_{t}$ is assumed constant, $\xi_{t}=\xi$, the orthogonality of $\varepsilon_{t+1} w 1$ th $R_{t}$ and $r_{t}$ Implies that the slope coefficient $\beta$ in a regression of the form

$$
1 / 2\left(r_{t}-r_{t-1}\right)=\alpha+\beta\left(R_{t-1}-r_{t-1}\right)+\text { disturbance, }
$$

should have a probabllity limit of 1.0. An estimated value significantly different from 1.0 is inconsistent elther with the expectations theory or one of the maintalned hypotheses.

In fact, it has been documented by many researchers that slope coefficlents tend to be well below 1.0 in post-1914 data for the United States, of ten significantly so in terms of estimated standard errors. Point est Imates obtalned in a number of studies are reported in Table 1 . There we see that the slope coefflclent values are all well below 1.0 , with the exception of Mankiw and Miron's value for 1890-1914 and Campbell and Shiller's final value. 5 The former, which pertains to observations taken before the founding of the Federal Reserve, wlll be discussed in Section IV. The latter is accompanled by a rather large standard error and pertalns to an exceedingly long short rate. ${ }^{6}$

One possible explanation for these findings 1s, of course, that the expectations theory is simply untrue--but the quantitative extent of the discrepancy seems surprisingly large. Another possibllity is invalidity of the rational expectations (RE) hypothesis, ${ }^{7}$ but it seems unlikely that the same general type of systematic expectational error would prevall over different sample perlods. In any event, our proposed explanation is that $\xi_{t}$ is not constant--1.e., that there is a varlable term premium--and that monetary policy is conducted in a manner to be explained momentarily. The 
Table 1

Empirical Results. Two-Perlod Case

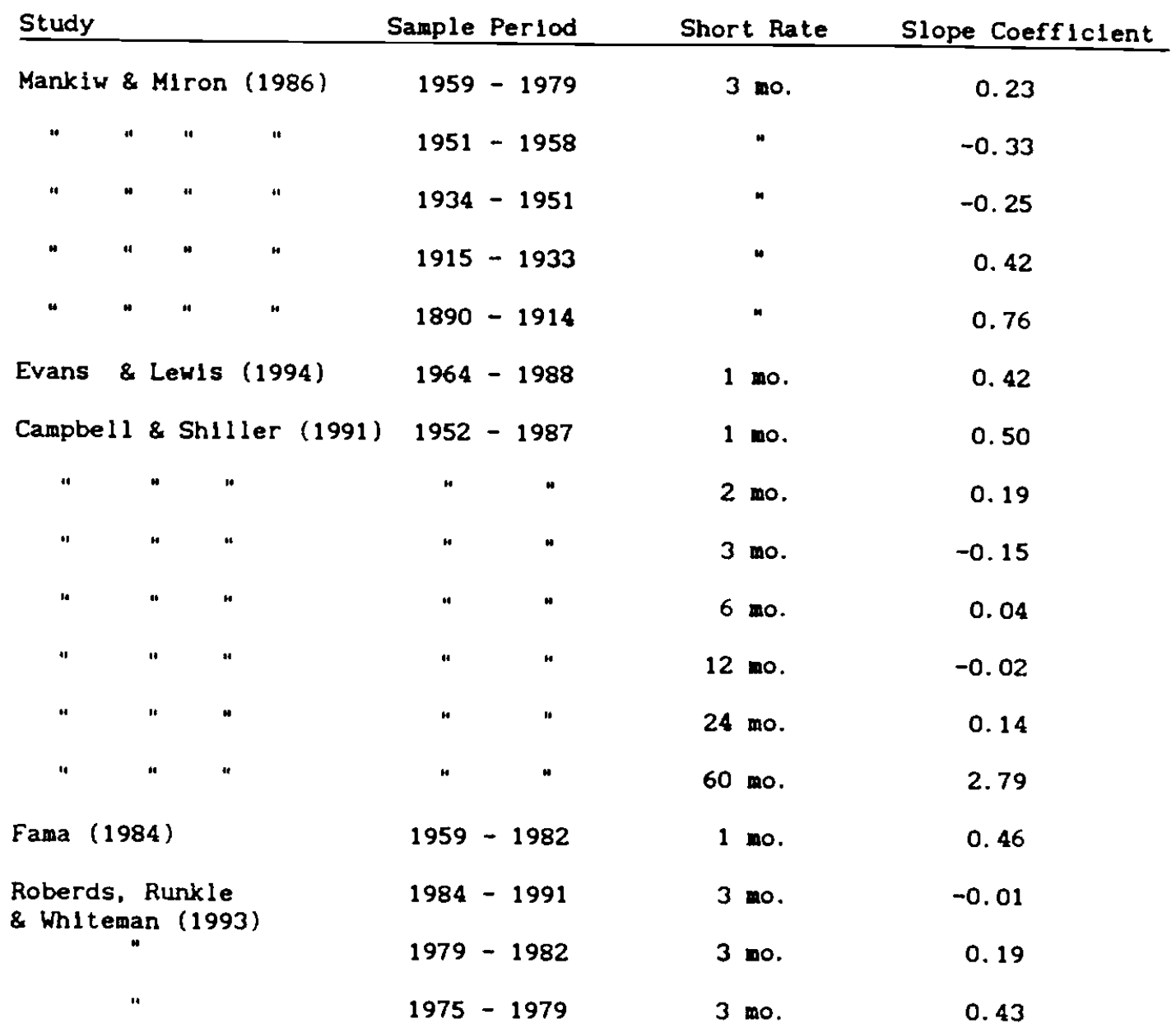


process generating $\xi_{t}$ is assumed to be covariance stationary but not necessarily white noise. For specificity, the $\xi_{t}$ process will be taken to be autoregressive of order one [AR (1)]:

(4) $\xi_{t}=\rho \xi_{t-1}+u_{t}$

Here $u_{t}$ is white noise and $|\rho|<1.0$. To this writer it seems implausible that there would not be some perlod-to-perlod varlability in the discrepancy term $\xi_{t}$ in (1), a term that reflects changes in tastes regarding the need for flnanclal flexibility and a myrlad of other disturbing influences, none major enough to justify separate recognition. In any event, it is not the case that the inclusion of a random $\xi_{t}$ disturbance in (1) converts the expectations theory into a tautology. That would be the case if $\xi_{t}$ were related to $r_{t}, E_{t} r_{t+1}$, and $R_{t}$ as in (1) without restriction. But instead the present assumption is that $\xi_{t}$ is exogenous with respect to $r_{t}$ and $R_{t}$. This reflects the ldea that the expected one-period holding ylelds on one-period and two-perlod bonds are equal up to a constant plus a random disturbance term; that these ylelds differ from that constant only randomly. This is, for the case at hand, the essence of the expectations theory.

Regarding monetary policy, our hypothesis begins with the observation that actual pollcy behavior in the U.S. (and many other nations) involves manipulation of a short-term interest rate "instrument" or "operating variable." Specifically, we assume that 8

$$
r_{t}=\sigma r_{t-1}+\lambda\left(R_{t}-r_{t}\right)+\zeta_{t}
$$

where $\sigma \geq 0$ is presumed to be close to 1.0 and $\lambda \geq 0$ to be smaller than 2.9 Thus there is a considerable element of interest rate "smoothing" -- keeping $r_{t}$ close to $r_{t-1}--$ and also a tendency to tighten policy (by raising ' $r_{t}$ ) whenever the spread $R_{t}-r_{t}$ is higher than normal. Whether this reaction to $R_{t}-r_{t}$ occurs because the central bank views it as a good predictor of future output growth or as a good indicator of recent policy laxity does not 
matter for current purposes. The final tern $\zeta_{t}$ reflects other components of policy behavior. It would not impair our analysis to let $\zeta_{t}$ be autocorrelated, but it would not help, elther. Accordingly, we shall assume that $\zeta_{t}$ is white nolse.

It may be helpful to brlefly consider the rationale for the specification of policy behavior in (5). Regarding the $r_{t-1}$ term, there exists some controversy regarding the reason behind central banks' proclivity for interest rate smoothing--and, indeed, for their use of interest rate instruments. But there is virtually no disagreement with the proposition that the Fed--and other major central banks--have in fact employed such practices during most (if not all) of the last 40 years. 10 (For some useful discussion, see Goodfriend (1991) and Poole (1991).) In addition (5) reflects the assumption that the central bank tends to tighten policy when the spread $R_{t}-r_{t}$ is large. One possible rationalization is that the spread is an indicator of monetary policy expansiveness, as suggested by Laurent (1988), so that an unusually high value indicates the need for corrective action. A different idea is that the spread provides an indicator of the state of the economy from a cyclical perspective. Various investigators, including Estrella and Hardouvelis (1991) and Hu (1993), have documented that spread measures have predictive value for future real GNP growth rates. Also, Mishkin (1990) has shown that a spread varlable has some predictive content for future inflation rates. Thus an attempt by the central bank to conduct a forward-looking countercyclical pollcy would call for a response of the type indicated in (5), 1.e., a tightening when $R_{t}-r_{t}$ is high. ${ }^{11}$ Admittedly, in actual practice the Fed has used other predictor varlables Instead of the spread. But to the extent that these and the spread are useful predictors, the pollcy response would be much the same as implied by (5). 
Relations (1) and (5) constitute only a portion, of course, of a macroeconomic system. But if we assume that the disturbances $\xi_{t}$ and $\zeta_{t}$ are independent of those in the remaining relations, the system will be recursive and the subsystem (1)(5) will determine $r_{t}$ and $R_{t}$ without reference to the other varlables or shocks. Whether the remainder of the model does or does not feature relations of the IS-LM type $1 \mathrm{~s}$ irrelevant, for example, as is the extent to which prices of goods are flexible. Let us consider, then, a rational expectations solution to the system (1)(5). 12

Presuming that attention is to be focused on the fundamental or bubble-free solution yielded by the minimal-state-variable (MSV) criterion discussed by McCallum (1983), we combine (1) and (5) to yield

$$
(1+\lambda) r_{t}=\sigma r_{t-1}+\lambda\left[1 / 2\left(r_{t}+E_{t} r_{t+1}\right)+\xi_{t}\right]+\zeta_{t}
$$

and seek values of the undetermined coefficients $\phi_{0}, \phi_{1}, \phi_{2}$, and $\phi_{3}$ that will provide a $r_{2}$ solution of the form

$$
r_{t}=\phi_{0}+\phi_{1} r_{t-1}+\phi_{2} \xi_{t}+\phi_{3} \zeta_{t} \text {. }
$$

Clearly, the latter implies that $E_{t} r_{t+1}=\phi_{0}+\phi_{1}\left(\phi_{0}+\phi_{1} r_{t-1}+\phi_{2} \xi_{t}+\phi_{3} \zeta_{t}\right)$ $+\phi_{2} \rho \xi_{2}$ so we substitute these into (6) to obtain

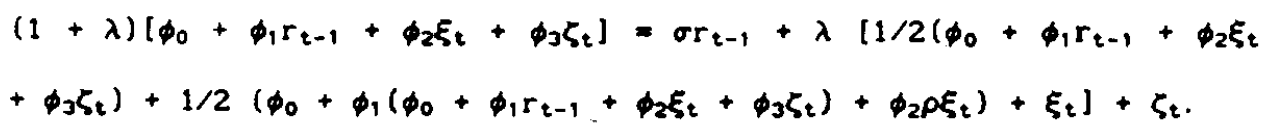
must be true that:

$$
\begin{aligned}
& (1+\lambda) \phi_{0}=\lambda \phi_{0}+1 / 2 \lambda \phi_{1} \phi_{0} \\
& (1+\lambda) \phi_{1}=\sigma+1 / 2 \lambda \phi_{1}+1 / 2 \lambda \phi_{1}^{2} \\
& (1+\lambda) \phi_{2}=1 / 2 \lambda \phi_{2}+1 / 2 \lambda \phi_{1} \phi_{2}+1 / 2 \lambda \rho \phi_{2}+\lambda \\
& (1+\lambda) \phi_{3}=1 / 2 \lambda \phi_{3}+1 / 2 \lambda \phi_{1} \phi_{3}+1
\end{aligned}
$$

The second of these is satisfled by two values of $\phi_{1}$, namely,

$$
\phi_{1}=\frac{(1+\lambda / 2) \pm\left[(1+\lambda / 2)^{2}-2 \lambda \sigma\right]^{1 / 2}}{\lambda}
$$


but the MSV criterion Implies that the one with the minus sign is relevant. ${ }^{13}$ Then the remalning coefficlents are stralghtforwardly given by the other three equalities in (9).

In analyzing the lmplications of this solution it wll be useful to emphasize the lmportant special case Involving $\sigma=1$, which is the value suggested by interest rate smoothing behavior. When $\sigma=1$, the MSV solution for $\phi_{1}$ becomes $[(1+\lambda / 2)-(1-\lambda / 2)] / \lambda=\lambda / \lambda=1$ and the other three equalities in (9) are simplifled considerably. They yleld $\phi_{0}=0, \phi_{2}=\lambda /(1$ - $\rho \lambda / 2)$, and $\phi_{3}=1$ so the solution for $r_{t}$ is (11) $r_{t}=r_{t-1}+\frac{\lambda}{(1-\rho \lambda / 2)} \xi_{t}+\zeta_{t}$.

Furthermore, $E_{t} r_{t+1}-r_{t}=\phi_{2} \rho \xi_{t}$ so we find that the spread obeys

$$
R_{t}-r_{t}=1 / 2\left(E_{t} r_{t+1}-r_{t}\right)+\xi_{t}=(1-\rho \lambda / 2)^{-1} \xi_{t} .
$$

Finaliy, equations (11) and (4) $1 \mathrm{mply}$

$$
r_{t}-r_{t-1}=\frac{\lambda \rho}{1-\lambda \rho / 2} \xi_{t-1}+\frac{\lambda}{1-\lambda \rho / 2} u_{t}+\zeta_{t}
$$

so we can combine (12) and (13) to obtaln

$$
1 / 2\left(r_{t}-r_{t-1}\right)=\frac{\lambda \rho}{2}\left(R_{t-1}-r_{t-1}\right)+\frac{\lambda / 2}{1-\rho \lambda / 2} u_{t}+1 / 2 \zeta_{t} .
$$

But here $u_{t}$ and $\zeta_{t}$ are uncorrelated with $R_{t-1}-r_{t-1}$, so (14) represents a population version of the regression described in (3). Thus the slope coefficlent in (3) is a consistent estimator of $\rho \lambda / 2$, so the analyst should anticlpate a slope well below 1.0. Indeed, if $\xi_{t}$ were white nolse, with $\rho=0$, a slope coefficlent of zero would be Implied -- even though relation (1) is the main behavioral relation of the system. That result demonstrates, I would suggest, not only that the usual regression test is inapproprlate but also that it is misleading to think of the expectations theory in terms of the "predictive content" of the spread for future changes of the short rate. Such predictive content is not a necessary Implication of that theory.

In addition, a zero slope coefficlent would be Implied if $\lambda=0,1$.e. if the central bank did not respond to the current value of the spread but 
simply set $r_{t}$ equal to $r_{t-1}$ (plus, perhaps, $\zeta_{t}$ ). This special case, of the speclal case with $\sigma=1$, represents the hypothesls of Mankiw and Miron (1986)--that the Federal Reserve has practlced Interest rate smoothing and thereby induced short rates to approximate a random walk process in their behavior. Our result strongly supports the general Idea of the Mankiw and Miron hypothesis, but shows that it holds even if $r_{t}$ behavior is not that of a random walk.

A few readers have remarked that (14) appears to be Inconsistent with the fact that a regression of form (3) should yleld a slope coefficlent of 1.0 in the special case in which the term premium $\xi_{t}$ is a constant. But with $\sigma=1.0$ in (5), a constant $\zeta_{t}$ impiles that $R_{t}-r_{t}$ is also constant--see equation (12). Thus there is a degenerate regressor, in this case, so the regression cannot be conducted. And in the case with $\sigma<1.0$, (14) does not apply so again there is actually no inconsistency.

Let us now brlefly consider the situation with $\sigma<1$. In such cases we would need to include a non-zero constant term in (5) to permit a stationary equilibrlum with $E \zeta_{t}=0$. The solution in this case ylelds a relationship analogous to (14) that is less tidy than the latter, and includes additional predetermined varlables. But it remalns true that the probabllity limit of the slope coefficient in a regression of $r_{t}-r_{t-1}$ on $R_{t-1}-r_{t-1}$ is not in general equal to 1.0 and is most likely to be smaller than 1.0 ; a demonstration is provided in Appendix A. Accordingly, the same general message applies as in the more tractable case with $\sigma=1$. That message is that the realization of (say) a positive value of $\xi_{t}$ will drive up $R_{t}$ relative to $r_{t}$ via (1). But then $R_{t}-r_{t}$ wlll be negatively correlated with the composite disturbances $-\xi_{t-1}+0.5 \varepsilon_{t+1}$ in (3), Implying that leastsquares estimation of (4) will yleld a slope coefficient that has a probability $11 \mathrm{mlt}$ not equal to 1.0 . 


\section{II. N N-Period Case}

Now we turn to the more interesting case in which the long rate, $R_{t}$, is for a bond with a maturity of more than two perlods. In this case an approximation to the expectations-hypothesis relationship between $R_{t}$ and $r_{t}$ can be written as

$$
R_{t}-N E_{t}\left(R_{t+1}-R_{t}\right)=r_{t}+\xi_{t},
$$

where $N+1$ is a measure of the duration of the long rate. ${ }^{14}$ In (5) the left-hand side is an approximation to the one-period holding return on the long-rate bond, the inexactness arising because the term $R_{t+1}$ should pertain to a maturity one period less than that for $R_{t}$. Thus for many-perlod maturities, the approximation should be adequate. ${ }^{15}$

In this case the apparent empirical fallure to be explained arises from writing (15) as

(16) $N\left(R_{t+1}-R_{t}\right)=\left(R_{t}-r_{t}\right)-\xi_{t}+N \varepsilon_{t+1}$,

where $\varepsilon_{t+1}=R_{t+1}-E_{t} R_{t+1}$ is an expectational error that with $R E$ is uncorrelated with $R_{t}$ and $r_{t}$. Thus if $\xi_{t}$ were constant, the slope coefficlent in a regression of $N\left(R_{t+1}-R_{t}\right)$ on $R_{t}-r_{t}$ should have a probability limit of 1.0 according to the expectations theory. But such regressions again actually yleld slopes well below 1.0 with U.S. data. Indeed, the values reported by Evans and Lewis (1994) and Campbell and Shiller (1991) are predominantly negative, as is documented in Table 2, and increase in absolute value with $N$.

As in the last section we assume that the policy reaction equation (5) obtains with $\lambda<1 / N$ and that $\xi_{t}=\rho \xi_{t-1}+u_{t}{ }^{16}$ Then one can combine (5) and (15) to obtain

$$
(1+N) R_{t}=N E_{t} R_{t+1}+(1+\lambda)^{-1}\left[\sigma r_{t-1}+\lambda R_{t}+\zeta_{t}\right]+\xi_{t} .
$$

The MSV solution will be of the form

$$
R_{t}=\pi_{1} r_{t-1}+\pi_{2} \xi_{t}+\pi_{3} \zeta_{t}
$$


Table 2

Empirical Results, N Perlod Case

\begin{tabular}{|c|c|c|c|c|c|c|c|c|}
\hline Study & & & Sample & Period & Short Rate & $\mathrm{N}+1$ & Slope & Coeff \\
\hline Evans & \& Lewis & (1994) & 1964 & -1988 & 1 no & 2 & & -0.17 \\
\hline " & * " & & $"$ & $"$ & * & 4 & & -0.70 \\
\hline$"$ & " " & & $"$ & $"$ & $"$ & 6 & & -1.27 \\
\hline$"$ & $" \quad "$ & & - & $"$ & $"$ & 8 & & -1.52 \\
\hline$"$ & " & & $"$ & $"$ & 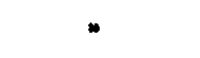 & 10 & & -1.89 \\
\hline Campb & $\begin{array}{l}\text { el1 \& Sh1 } \\
(1991)\end{array}$ & ller & 1952 & -1987 & 1 mo & 2 & & 0.00 \\
\hline$"$ & $"$ & $"$ & $"$ & $"$ & $"$ & 4 & & -0.44 \\
\hline " & $"$ & $"$ & $"$ & $"$ & $"$ & 6 & & -1.03 \\
\hline$"$ & $"$ & $"$ & $"$ & $"$ & $"$ & 12 & & -1.38 \\
\hline " & $"$ & $"$ & $"$ & $n$ & $"$ & 24 & & -1.81 \\
\hline " & $"$ & $"$ & $"$ & $"$ & $"$ & 48 & & -2.66 \\
\hline$"$ & " & $"$ & $"$ & $"$ & $"$ & 60 & & -3.10 \\
\hline " & " & " & " & " & $"$ & 120 & & -5.02 \\
\hline Hardo & uvelis ( 1 & (994) & 1954 & -1992 & 3 mo & 120 & & -2.90 \\
\hline
\end{tabular}


Implying $E_{t} R_{t+1}=\pi_{1}(1+\lambda)^{-1}\left[\sigma r_{t-1}+\lambda\left(\pi_{1} r_{t-1}+\pi_{2} \xi_{t}+\pi_{J} \zeta_{t}\right)+\zeta_{t}\right]+\pi_{2} p \xi_{t}$, which can be substituted with (18) into (17) to give

$(1+N)\left[\pi_{1} r_{t-1}+\pi_{2} \xi_{t}+\pi_{3} \zeta_{t}\right]=N \pi_{1}(1+\lambda)^{-1}\left[\sigma r_{t-1}+\lambda\left(\pi_{1} r_{t-1}+\pi_{2} \xi_{t}\right.\right.$ $\left.\left.+\pi_{3} \zeta_{t}\right)+\zeta_{t}\right]+N \pi_{2} \rho \xi_{t}+(1+\lambda)^{-1}\left[\sigma r_{t-1}+\lambda\left(\pi_{1} r_{t-1}+\pi_{2} \xi_{t}+\pi_{3} \zeta_{t}\right)+\zeta_{t}\right]+\xi_{t}$.

For (18) to be a solution, then, we must have

$$
\begin{aligned}
& (1+N) \pi_{1}=N \pi_{1}(1+\lambda)^{-1}\left(\sigma+\lambda \pi_{1}\right)+(1+\lambda)^{-1}\left(\sigma+\lambda \pi_{1}\right) \\
& (1+N) \pi_{2}=N \pi_{1}(1+\lambda)^{-1} \lambda \pi_{2}+N \pi_{2} \rho+(1+\lambda)^{-1} \lambda \pi_{2}+1 \\
& (1+N) \pi_{3}=N \pi_{1}(1+\lambda)^{-1}\left(\lambda \pi_{3}+1\right)+(1+\lambda)^{-1}\left(\lambda \pi_{3}+1\right)
\end{aligned}
$$

The first of these amounts to $(1+\lambda)(1+N) \pi_{1}=\left(N \pi_{1}+1\right)\left(\sigma+\lambda x_{1}\right)$ so we have

$$
\pi_{1}=\frac{[(1+\lambda)(1+N)-\lambda-N \sigma] \pm\left\{[(1+\lambda)(1+N)-\lambda-N \sigma]^{2}-4 N \lambda \sigma\right\}^{1 / 2}}{2 N \lambda}
$$

The term in square brackets will be positive, so the MSV solution for $\pi$, is the expression in (21) with the minus sign. 17 Given this value, the second and third of equations (20) determine $\pi_{2}$ and $\pi_{3}$.

To facllitate analysis, let us again focus attention on the case with $\sigma$ $=1$. Then we have $[(1+\lambda)(1+N)-(\lambda+N)]^{2}=(1+\lambda)^{2}(1+N)^{2}-2(1+\lambda)$ $(1+N)(\lambda+N)+(\lambda+N)^{2}=1+2 N \lambda+N^{2} \lambda^{2}$ and the term inside curly brackets In (21) becomes $1-2 N \lambda+N^{2} \lambda^{2}=(1-N \lambda)^{2}$. Consequent $]$, we have $\pi_{1}=[(1+$ $N \lambda)-(1-N \lambda)] / 2 N \lambda=1$, where the last calculation ut111zes the assumed condition $1-N \lambda>0$. Then with $\pi_{1}=1$, the final equation in (20) 1mplies $\pi_{3}$ $=1$ and $\pi_{2}=(1+\lambda) /[1+N-N \rho(1-\lambda)]$. Because $1>N \lambda, \pi_{2}$ is strlctly positive. Given these values, we readlly see that

$$
R_{t}=r_{t-1}+\frac{1+\lambda}{1+N-N \rho(1+\lambda)} \xi_{t}+\zeta_{t}
$$

$$
r_{t}=r_{t-1}+\frac{\lambda}{1+N-N \rho(1+\lambda)} \xi_{t}+\zeta_{t} .
$$

Accordingly, the spread varlable obeys 


$$
R_{t}-r_{t}=\frac{1}{1+N-N \rho(1+\lambda)} \xi_{t}
$$

and using (22) and (4) we also have

$$
\begin{aligned}
& R_{t}-R_{t-1}= \frac{\lambda+1}{1+N-N \rho(1+\lambda)} \xi_{t}-\frac{1}{1+N-N \rho(1+\lambda)} \xi_{t-1}+\zeta_{t} \\
&= \frac{(\lambda \rho+\rho-1) \xi_{t-1}+(1+\lambda) u_{t}}{1+N(1-\rho(1+\lambda))}+\zeta_{t} \\
&=(\lambda \rho+\rho-1)\left(R_{t-1}-r_{t-1}\right)+\frac{(1+\lambda)}{1+N(1-\rho(1+\lambda))} u_{t}+\zeta_{t} .
\end{aligned}
$$

Consequently, we see that a regression of $N\left(R_{t}-R_{t-1}\right)$ on $R_{t-1}-r_{t-1}$ will have a slope coefficient whose probability limit is $N(\lambda \rho+\rho-1)$ or $-N(1-\rho(1+\lambda))$. Clearly, the latter will be negative except for very large values of $\rho$ and/or $\lambda$, and will be larger in absolute value (for a given $\rho$ ) with longer maturities (larger $N$ ). ${ }^{18}$ In qualitative terms, both of these characteristics match the results of Evans and Lewis (1994) and Campbell and Shiller (1991) reported in Table 2.

\section{Additional Evidence}

The paper by Campbell and Shiller (1991) concludes with an attempt to provide a summary characterization of term structure behavior that would be consistent with their battery of empirical findings, which include many more than those reported here. In their words, "The explanations we will consider are not finance-theoretic models of time-varying risk premia, but simply econometric descriptions of ways in which the expectations theory might fail" (1991, p. 510). In terms of the notation of the present paper, the two summary characterizations considered are (for the two-period case)

$$
R_{t}-r_{t}=0.5 E_{t}\left(r_{t+1}-r_{t}\right)+c+v_{t} \text {. }
$$

where $v_{t}$ is added noise that is orthogonal to $E_{t} r_{t+1}-r_{t}$, and

$$
R_{t}-r_{t}=k 0.5 E_{t}\left(r_{t+1}-r_{t}\right)+c
$$

where $k>1$. The latter "could be described as an overreaction model of the 
yield spread," according to Campbell and Shiller (1991, p. 513). They explore the implications of these two summary characterizations of ways in which the expectations theory ight fall and conclude that (27) is consistent with the data but that (26) is not.

Let us consider how these characterizations compare with the explanation of the present paper. Looking back at Section II, we see that equation (12) is of a similar form to that of (26), but with the cruclal difference that $\xi_{t}$ In (12) is not orthogonal to $E_{t} r_{t+1}-r_{t}$. Thus the inadequacy of (26) does not serve to discredit the model of Section II. Furthermore, using the expression $E_{t} r_{t+1}-r_{t}=\phi_{2} \rho \xi_{t}$ to eliminate $\xi_{t}$ from (12) results in

$$
R_{t}-r_{t}=(1 / \rho \lambda) E_{t}\left(r_{t+1}-r_{t}\right)
$$

for the model of Section II. But $w 1$ th $0<\lambda<2$ and $|\rho|<1$, (28) 1 mplies that $k>1$ In (27) if $\rho$ is positive. So Campbell and Shiller's summary characterization is consistent with the present paper's rationalization. 19

It was mentioned above that the slope coefficlent reported in Table 1 for the years 1890 - 1914 was closer (than for more recent perlods) to the value of 1.0 that has been focused on in previous investigations. As Mankiw and Miron (1986) emphasize, those years precede the founding of the Federal Reserve System and therefore pertain to a perlod during which interest rate smoothing behavior would be absent. In a similar vein, Kugler (1988, 1990) finds that slope coefficlents are closer to 1.0 for Germany and Switzerland than for the United States during recent years. This result he attributes to a smaller degree of interest smoothing behavior by the Bundesbank and the Swiss National Bank, in comparison with the Fed, a hypothesized behavioral difference that is consistent with the bellefs of many students of central banking behavior. Since the model in Sections II and III presumes a substantial degree of interest rate smoothing, this paper's explanation is consistent with both of these findings. 20 
V. Concluding Remarks

The discussion of the foregoing paragraph suggests that one possible way of conducting additional tests of this paper's hypothesis would be to consider different monetary policy regimes corresponding to different time periods for the United States and to different nations. Reaction functions corresponding to (5) would be estimated and the implications of their parameter values for the cruclal slope coefficients then compared with values of the coefficients obtained for these different regimes. Now, it may prove possible to make some progress toward execution of such a study. There 1s, however, a substantial difficulty that needs to be mentioned. Specifically, It is the case that actual central banks do not respond only to term spreads in deciding upon changes in $r_{t}$. Thus equation (5) represents a simplification relative to actual behavior of the Fed, which almost certainly responds to recent inflation and output or employment movements as well as the spread. So, if one were to attempt to econometrically estimate actual reaction functions, then measures of inflation and output gaps would need to be included. But in that case values of these varlables would need to be explained endogenously, so the system of equations in the model would have to be expanded. Furthermore, the dynamic behavior of inflation and output would need to be modeled "correctly," which is an exceedingly difficult task given the absence of professional agreement about short-run macroeconomic dynamics. In short, this type of study would require specification and estimation of a complete dynamic macroeconometric model.

In light of the foregoing discussion it will be seen that, because of the simplified nature of our policy equation (5), this paper's proposed explanation might be regarded as more of a parable than a fully-worked-out quantitative model. I would argue, however, that this is not a source of embarrassment, for most knowledge in economics is actually of the parable 


\begin{abstract}
type. 21 The relevant issue is whether a proposed parable is frultful in understanding Important economic phenomena. In this particular case the proposed parable suggests that slope estimates in regressions of the form (3) or (16) differ from 1.0 desplte the validity of a version of the expectations theory of the term structure. This version permits the holding-perlod ylelds on securitles of various maturities to differ by a randow discrepancy that is exogenous but perhaps serially correlated. The basic Idea of the parable is that the estimated slope coefficient is a composite parameter reflecting policy behavior as well as the behavior of market particlpants, with the type of pollcy postulated involving interest rate smoothing and response to the long-short spread, the latter reflecting Important aspects of the state of the economy. The fact that essentlally the same parable can rationallze a major anomaly in forelgn exchange markets must be regarded as a slgnificant mark in its favor.
\end{abstract}


References

Campbel1, John Y., and Robert J. ShIller, "Yleld Spreads and Interest Rate Movements: A Bird's Eye Vlew," Review of Economlc Studies 58 (1991), 495-514.

Canzoner1, Matthew B., Dale W. Henderson, and Kenneth S. Rogoff, "The Information Content of the Interest Rate and Optimal Monetary Pollcy," Quarterly Journal of Economics 98 (November 1983), 545-566.

Cook, Timothy, and Thomas Hahn, "Interest Rate Expectations and the Slope of the Money Market Yleld Curve," Federal Reserve Bank of Richmond Economlc Revlew 76 (No. 5, 1990), 3-26. and " The Effect of Changes in the Federal Funds Rate Target on Market Interest Rates in the 1970s, " Journal of Montary Economics 24 (November 1989), 331-351.

Dotsey, Michael, and Robert G. KIng, "Monetary Pollcy Instruments and Pollcy Rules in a Rational Expectations Environment," Journal of Monetary Economics 12 (September 1983), 357-382.

Estrella, Arturo, and Gikas A. Hardouvelis, "The Term Structure as a Predictor of Real Economic Activity," Journal of Flnance 46 (June 1991), 555-576.

Evans, Martin D.D., and Karen K. Lewls, "Do Statlonary Risk Premla Explain It All? Evidence from the Term Structure," Journal of Monetary Economics 33 (Apr11 1994), 285-318.

Fama, Eugene F.. "The Information in the Term Structure," Journal of Financial Economics 13 (Dec. 1984), 509-528.

Froot, Kenneth A., "New Hope for the Expectations Hypothesis of the Term Structure of Interest Rates," Journal of Finance 44 (June 1989), 283-305. 
Fuhrer, Jeffrey C., and George Moore, "Monetary Pollcy and the Behavlor of Long-Term Real Interest Rates," Finance and Economics Discussion Serles 93-16, Board of Governors of the Federal Reserve System, 1993.

Goodfriend, Marvin, "Interest Rate Policy and the Inflation Scare Problem," Federal Reserve Bank of Richmond Economle Quarterly 79 (No. 1, 1993), $1-24$.

Carnegle-Rochester Conference Series on Public Pollcy 34 (Spring 1991), 7-30.

Hardouvel1s, Gikas A., "The Term Structure Spread and Future Changes in Long and Short Rates in the G7 Countries: Is There a Puzzle?" Journal of Monetary Economlcs 33 (Apr11 1994), 255-283.

Hu, Zullu, "The Yleld Curve and Real Activity," IMF Staff Papers 40 (December 1993), 781-806.

Kugler, Peter, "An Emplrical Note on the Term Structure and Interest Rate Stabilization Policles," Quarterly Journal of Economics 103 (November 1988), 789-792.

"The Term Structure of Euro Interest Rates and Rational

Expectations," Journal of International Money and Finance 9 (1990), $234-244$

Laurent, Robert D., "An Interest Rate-Based Indicator of Monetary Policy," Federal Reserve Bank of Chlcago Economic Perspectives 12 (January/ February 1988), 3-14.

Mankiw, N. Gregory, and Jeffrey A. Miron, "The Changing Behavior of the Term Structure of Interest Rates," Quarterly Journal of Economics 101 (May 1986), 211-228. 
McCallum, Bennett T., "Price Level Determinacy With an Interest Rate Pollcy Rule and Rational Expectations," Journal of Monetary Economics 8 (November 1981), 319-329. - "On Non-Uniqueness in Rational Expectations Models: An At tempt at Perspective," Journal of Monetary Economics 11 (1983). $139-168$.

Level Determinacy, and the Real Bills Doctrine," Journal of Monetary Economics 17 (January 1986), 135-160. "A Reconsideration of the Uncovered Interest Parity Relationship," Journal of Monetary Economics 33 (February 1994), $105-132$.

McCulloch, J. Huston, "The Term Structure of Interest Rates: Appendix B," Handbook of Monetary Economles, ed. by B.M. Friedman and F.H. Hahn. Amsterdam: North-Holland Pub. Co., 1990.

Mishkin, Frederic S., "The Information in the Longer Maturity Term Structure about Future Inflation," Quarterly Journal of Economics 105 (December 1990). 815-828.

Poole, William. "Interest Rates and the Conduct of Monetary Policy: A Comment," Carnegle-Rochester Conference Series on Public Pollicy 34 (Spring 1991), 31-40.

Roberds, William, David Runkle, and Charles H. Whiteman, "Another Hole in the Ozone Layer: Changes in FOMC Operating Procedure and the Term Structure," Operating Procedures and the Conduct of Monetary Pol1cy: Conference Proceedings, edited by Marvin Goodfriend and David H. Small. Finance and Economics Discussion Series, Federal Reserve Board, March 1993.

Rudebusch, Glenn D., "Federal Reserve Interest Rate Targeting and the Term Structure," Working Paper, May 1994. 
Shiller, Robert J., "The Term Structure of Interest Rates," Handbook of Monetary Economics, ed. by B.M. Frledman and F.H. Hahn. Amsterdam: North-Holland Pub. Co., 1990.

"The Volatility of Long-Term Interest Rates and Expectations Models of the Term Structure," Journal of Polftical Economy 87 (December 1979), 1190-1219.

Shiller, Robert J., John Y. Campbell, and Kermit L. Schoenholtz, "Forward Rates and Future Policy: Interpreting the Term Structure of Interest Rates." Brookings Papers on Economic Activlty (No. 1, 1983), 173-217. 


\section{Footnotes}

1The hypothesized form of policy behavior involves smoothing of (relative) interest rates, with these rates used as instruments, together with policy attempts to "lean against" exchange rate changes. The analysis also assumes random disturbances--from varying risk prenia--to the UIP relationship. No departure from rational expectations is involved.

${ }^{2}$ General aspects of the fallure are discussed by Cook and Hahn (1990), Campell and Sh1ller (1991), and Evans and Lewls (1994), among others.

${ }^{3}$ Since drafting this paper I have become aware of a study with a rather similar objective by Rudebusch (1994), which is also intended to provide a generalization of the Mankiw-Miron hypothesis. The type of policy behavior assumed there is quite different, however, as instrument settings are responsive to current conditions in my setup but are determined exogenously in his. Most significantly, Rudebusch's analysis does not offer an explanation for the empirical phenomena rationalized below at the end of Section III and in Section IV.

"The relationship is exact, if the interest rates are based on continuous compounding, or an approximation otherwise: see Shiller (1990).

${ }^{5}$ An analogous result holds for the case of three-month and one-month rates; see Kugler (1988, 1990).

${ }^{6}$ The Roberds, Runkle, and Whiteman (1993) results are for treasury bills. This study also reports results using Federal Funds and Repo securities and finds one slope coefficlent close to 1.0 for the former using the sample period 1979.10 - 1982.10.

${ }^{7}$ This possibility has been explored, using survey data on expectations, by Froot (1989). 
${ }^{8}$ For values of $\sigma$ less than 1.0 , a constant term should also be included in (5) If $E \zeta_{t}=0$. We have not shown it here, however, because the case with $\sigma$ $=1$ will be featured below and because little interest attaches to the constant term in any case.

${ }^{9}$ In what follows, $\lambda<2$ will be presumed because such a condition seems plausible and also because a theoretical issue, concerning the root of (10) that gives the bubble-free solution, arises when $\lambda>2$. (On this issue see Appendix B.) But the solutions obtained below, and most of the analysis, would continue to prevall with $\lambda \geq 2$.

${ }^{10}$ Some analysts are dublous that the Fed's control over the one-day Federal Funds rate translates into effective control over one-month or three-month treasury bill rates that are the operational counterpart of $r_{t}$ in (5). But the evidence of Cook and Hahn (1989) suggests that three-month rates do, in fact, respond within the day to policy-induced changes in the Federal Funds rate. Furthermore, if the Fed doubted its abllity to control treasury b111 rates it could (given its holdings) operate directly in the treasury bill markets. Consequently, doubts concerning the controllability of $r_{t}$ seem to be unfounded. 
11 In an influential recent publication, Goodfriend (1993) suggests that the Fed regards (or should regard?) the long rate as an Indlcator of "Inflation scares," behavior that mlght be interpreted as descriptive of a rule of the form $r_{t}=\delta r_{t-1}+\theta\left(R_{t}-\vec{R}\right)+\zeta_{t}$. The latter can be written in the form (5) by defining $\sigma=\delta /(1-\theta)$ and $\lambda=\theta /(1-\theta)$, but then dynamic stab1lity (non-explosiveness) requires $\delta<1-\theta$ (assuming that $0<\theta<1$ ). It is not clear that Goodfriend would agree with the above formulation, however: another possibllity is $r_{t}=r_{t-1}+\theta\left(R_{t}-R_{t-1}\right)+\zeta_{t}$. In any event, the pollcy behavior pattern in his article has a substantlal degree of simllarity with formulation (5): both call for an increase in the short rate in response to a ceteris paribus $r$ ise in the long rate.

${ }^{12}$ Students of the price level determinacy literature--e.g., McCallum (1981) (1986), Dotsey and King (1983), Canzoner1, Henderson, and Rogoff (1985)--w111 wonder about the absence of nominal varlables in the system (1)(5). But the price level can be brought in by adding (e.g.) an IS-type relation in which a real rate such as $r_{t}-\left(E_{t} p_{t+1}-p_{t}\right)$ appears, $p_{t}$ being the $10 g$ of the price level. Then determinacy of $p_{t}$ will require the presence of an additional term in (5), one that includes a nominal varlable such as $p_{t}$ or $E_{t} p_{t+1}$ or $p_{t-1}$. Algebralc analysis becomes much more difflcult because the counterpart of (10) below will be a cublc in many such cases. But a cublc must have at least one real root, so in princlple determinacy can be Investigated. My examination of a case with $p_{t}$ included in (5) Indicates that determinacy would be guaranteed unless $\sigma=1.0$ exactly. Thus for $\sigma$ close to 1.0 , the results would be approximately the same as those emphaslzed below.

${ }^{13}$ This is the root that yields $\phi,=0$ when $\sigma=0$, a special case in which it is clear that $r_{t-1}$ would be an extraneous state varlable [as discussed in McCallum (1983)]. 
${ }^{14}$ For pure discount bonds, $\mathrm{N}+1$ is the maturity.

${ }^{15}$ Equation (15) can alternatively be written as $R_{t}=(1-\delta) \Sigma \delta^{k} E_{t} r_{t+k}+$ term premium, with the summation from 0 to $\infty$. Thus the approximation amounts to an infinite-maturity version of the linearization developed by Shiller (1979), with $N=\delta /(1-\delta)$. This approximation has also been used by Shiller, Campbell, and Schoenholtz (1983), Campbell and Shiller (1991), Fuhrer and Moore (1993), and Hardouvelis (1994).

${ }^{16}$ The condition $\lambda<1 / N$ is the counterpart of $\lambda<2$ in the two period case (in which $N=1$ ) and is again presumed but not strictly required. The larger is $N$, the smaller will be $\lambda$ in equation (5) because only one $\lambda$ can prevall, but many long rates can be considered.

${ }^{17}$ Again this is because with $\sigma=0, r_{t-1}$ should not appear in the solution for $R_{t}$.

${ }^{18}$ The policy parameter $\lambda$ would be expected to be smaller for larger $N$. This effect relnforces the tendency for the slope coefficlent to increase in absolute value with $\mathrm{N}$.

${ }^{19}$ The foregoing discussion implies, incidentally, that there is actually nothing bizarre or 1rrational about a finding expressible as $k>1$ in (27).

${ }^{20}$ For additional discussion of the Mankiw-Miron hypothesis, see Cook and Hahn (1990).

${ }^{21}$ Consider the usual depiction of a production function as $y_{t}=f\left(n_{t}, k_{t}\right)$, where the symbols should not require definition. Can this depiction be considered anything more than a parable? 
Append IX A

Here the concern is with the model of Section II when $\sigma<1.0$. From (9), we find that

(A-1) $\quad r_{t}=\phi_{0}+\phi_{1} r_{t-1}+\frac{\lambda}{\delta-\rho \lambda / 2} \xi_{t}+\frac{1}{\delta} \zeta_{t}$

where $\delta=1-\left(\phi_{1}-1\right) \lambda / 2$. Then from $(A-1)$ it follows that

$(A-2) \quad E_{t} r_{t+1}-r_{t}=\phi_{0}+\left(\phi_{1}-1\right) r_{t}+\lambda \rho /(\delta-\rho \lambda / 2) \xi_{t}$

and thus using (12) that

$(A-3) \quad R_{t}-r_{t}=(1 / 2)\left[\phi_{0}+\left(\phi_{1}-1\right) r_{t}+(p \lambda /(\delta-p \lambda / 2)) \xi_{t}\right]+\xi_{t}$.

Now, equation (2) Indicates that the plin of the slope coefficient on $R_{t}-r_{t}$ In the regression (3) will equal 1.0 minus plim $T^{-1} \xi_{t}\left(R_{t}-r_{t}\right) / p l I m T^{-1}\left(R_{t}-\right.$ $\left.r_{t}\right)^{2}$. Its value $w 111$ be smaller than 1.0, then, if $E F_{t}\left(R_{t}-r_{t}\right)$ is positive.

From $(A-3)$ it is clear that there are two components to $E \xi_{t}\left(R_{t}-r_{t}\right)$. One of these is

$(A-4) \quad\left(\frac{\rho \lambda / 2}{\delta-\rho \lambda / 2}+1\right) \sigma_{\xi}^{2}$,

which is necessarlly positive since the tern in parentheses equals

(A-5) $\frac{1+\left(1-\phi_{1}\right) \lambda / 2}{1+\left(1-\phi_{1}\right) \lambda / 2-\rho \lambda / 2}$.

Here $\left(1-\phi_{1}\right) \lambda / 2$ is positive, since $\phi_{1}<1$ when $\sigma<1$ (see below), and $|\rho \lambda / 2|<1$.

Thus expression $(A-5)$ is unamblguously positive. The second component is

$(A-6) \quad(1 / 2)\left(\phi_{1}-1\right) \operatorname{Er}_{t} \xi_{t}$.

in which the term $\phi_{1}-1$ is negative but wlll be small for $\sigma$ (and $\phi_{1}$ ) close to 1.0. To sign $E r_{t} \xi_{t}$, we use $(A-1)$ and (4) as follows, assuming $E \xi_{t} \zeta_{t}=0$ :

$(A-7) \quad E r_{t} \xi_{t}=E\left[\phi_{0}+\phi_{1} r_{t-1}+\phi_{2} \xi_{t}+\phi_{3} \zeta_{t}\right] \xi_{t}$

$=\phi_{1} E r_{t-1} \xi_{t}+\phi_{2} \sigma_{l}^{2}=\phi_{1} E r_{t-1} \rho \xi_{t-1}+\phi_{2} \sigma_{l}^{2}$.

Then since $\operatorname{Er}_{t} \xi_{t}=\operatorname{Er}_{t-1} \xi_{t-1}$, we have

(A-8) $\quad E r_{t} \xi_{t}=\frac{\phi_{2} \sigma_{\xi}^{2}}{1-\phi_{1} p}$.

The latter is unambiguously positive since $\phi_{2}>0$ and $\left|\phi_{1} \rho\right|<1$. Thus the second component is negative but will tend to be small relative to the first. 
It remains to demonstrate that $\phi_{1}<1$ when $\sigma<1$. But we have found that $(A-9) \quad \phi_{1}=\frac{(1+\lambda / 2)-\left[(1+\lambda / 2)^{2}-2 \lambda \sigma\right]^{1 / 2}}{\lambda}$

With $0<\sigma<1$, we have $2 \lambda>2 \lambda \sigma>0$ so the term in square brackets is positive and larger than $(1-\lambda / 2)^{2}$. Thus the value of $\phi_{1}$ is smaller than when this term equals $(1-\lambda / 2)^{2}, 1$ e., when $\sigma=1$. But $\phi_{1}$ remains non-negative because the term in brackets is smaller than $(1+\lambda / 2)^{2}$. 
Appendix B

Here the purpose to explain the difficulty concerning the roots of (10), mentioned in footnote 9, that would obtain with $\lambda>2$. To see the issue, consider the case in which $\sigma=1$, so that the $\phi$, solutions are $[(1+\lambda / 2) \pm$ $\left.\left((1-\lambda / 2)^{2}\right)^{1 / 2}\right\} / \lambda$. Denote these solutions as $\phi_{1}^{(1)}$ and $\phi_{1}^{(2)}$ and define $\phi_{1}^{(1)}$ as $\left[(1+\lambda / 2)-\left((1-\lambda / 2)^{2}\right)^{1 / 2}\right\} / \lambda$ for $\lambda<2$. But then if $\lambda>2$, is the "same" root $\phi_{1}{ }^{(1)}$ equal to $[(1+\lambda / 2)-(1-\lambda / 2)]=1$ or to $[(1+\lambda / 2)+$ (1 $-\lambda / 2)] / \lambda=2 / \lambda$ ? Note that the latter is suggested by the convention that $\left(z^{2}\right)^{1 / 2}$ is a positive number regardless of the sign of $z$. But defining the relevant root as $\phi_{1}^{(1)}=1$ for all $\lambda>0$ seems more appropriate than making $\phi_{1}{ }^{(1)}$ equal to 1 or $2 / \lambda$ depending on whether $\lambda<2$ or $\lambda>2$. Then equations (11) - (14) are valid even with $\lambda>2$. (Similar considerations apply to equations (21) - (25) if we permit $N \lambda>1$.) 